\title{
Students' and Instructors' Opinions on the Implementation of Flipped Learning Model for Cello Education in Turkish Music
}

\author{
Burcu Avc1 Akbel \\ Correspondence: Burcu Avcı Akbel, Turkish Music State Conservatory, Yıldırım Beyazıt University, Ankara, Turkey.
}

Received: May 4, 2018

doi:10.11114/jets.v6i8.3256

Accepted: May 25, 2018

Online Published: June 8, 2018

URL: https://doi.org/10.11114/jets.v6i8.3256

\begin{abstract}
Flipped learning is based on more effective use of the time spent with the instructor in the classroom. This study is aimed at identifying students' and instructors' opinions on the use of flipped learning model in cello education in Turkish music. This is the first study whereby flipped learning model has ever been used in Turkish Music education and cello education. Opinions on the implementation of the model were obtained through semi-structured interviews separately prepared for students and instructors. The data were analyzed by using the content analysis method. According to the data from the interviews, it has been revealed that the flipped learning model can be used in cello education in Turkish Music and the 'imitation' element in mesk method, the most important teaching method in instrument education in Turkish music, can be supported by flipped learning model.
\end{abstract}

Keywords: flipped learning, Turkish music education, cello, video lessons

\section{Introduction}

In parallel to the rapid spread of the use and production of information and communication technologies in our age, the form of use of new technologies in field of education has also been changing. The continuously developing technology offers instructors and students numerous options on teaching methods. "There have been efforts to attain a paradigm shift from the 'behavioral' to 'constructivist' approach" depending on the developments and changes in this century (Kertil, 2008). This change has brought along new perspectives and approaches in education. Likewise, flipped learning is an educational process developed to facilitate and accelerate students' learning.

Flipped learning system is defined as "a model which, unlike the conventional teaching method, enable students to learn theoretical knowledge by their own at home and practice what they have learned at school" (Zownorega, 2013). "In general terms, flipped learning reverses the conventional flow of learning, requiring students to learn the subject, which is supposed to be instructed in the classroom by the instructor, from the material recorded in electronic environment by the instructor and during out-of-class hours" (Bergman and Sams, 2012). The term 'Flipping' in the Flipping Classroom concept is used according to the idea of interchange between classroom activities and home assignments" (Ash, 2012). This term is coined as 'flipped learning' as it displaces stages in the conventional classroom teaching. Whereas, pedagogically, it is defined as "a model in which the information is transferred out of the classroom in the teaching process, social and active learning activities are performed in the classroom, and which contains activities before and/or after the class (Abeysekera and Dawson, 2015)

According to Bishop and Verleger (2013), the mentioned teaching system is a method enabling students to do more problem-solving activities, individually or in groups, on the topics they are studying, and focus on the problems they encounter in their individual learning, while enabling the instructor to personally mentor the student. Nonetheless, this teaching system also supports individual learning by shooting videos of lessons and so offering the student the opportunity of access to information wherever and whenever they want. "Flipped learning model is the part of a broad educational movement, covering blended learning, inquiry-based learning and other educational approaches and flexible, effective means to ensure further reinforcement of the learned lesson" (Johnson, Becker, Estrada and Freeman, 2014). According to Toto and Nguyen (2009), flipped learning system offers students opportunities such as peer learning, active learning, problem-based learning, group activities, and ability to create custom information and apply the theoretical knowledge learned under the instructor's guidance. Additionally, the flipped learning system is a model which "contributes to learners in assuming much more responsibility for their own learning" (Fulton, 2012).

Briefly, learners learn subjects only in classroom environment and do their assignments at home in conventional 
learning. Whereas, in flipped learning system, students are expected to have access to course contents out of the school, perform assigned activities and do the assignments or activities on the subject within the classroom environment. So, students will be able to overcome possible challenges in learning more easily and quickly in frame of classroom activities and through the instructor's support. This method also provides advantages such as the opportunity of peer learning and practice accompanied by the instructor with prior overview of theoretical information, and receiving instant feedbacks.

There are numerous studies conducted on students' and/or instructors' opinions on the flipped learning model. (Bosner, Pickert\&Stibane, 2015; Tan, Brainard\&Larkin, 2015; Tune, Sturek, Basile, 2013; Kocabatmaz, 2016; Sirakaya, 2017; Wong, Ip\&Lopes, 2014). In all of the mentioned studies on the subject, it was revealed that students easily adopted and liked the flipped learning method and always preferred it rather than the conventional method. There are also studies on feasibility of the flipped learning method in education. (Gannod, Burge\&Helmick, 2008; Moravec, Williams, Aguilar-Roca\&O'Dowd, 2010; Sever, 2014; Strayer, 2011; Talbert, 2012; Wetterlund, 2008). All of the studies revealed that the flipped learning method increases success in education. While there are studies evidencing that the flipped learning model improved learning, there are also other studies in which the model did not affect success. (Moraros et al., 2015; Mortensen and Nicholson, 2015; Wong, Ip and Lopes, 2014). Most of the studies on the subject are in medicine, physics, chemistry, mathematics and English, while there are very few studies on the flipped learning model in field of music. This study analyzed feasibility of the flipped learning model for cello education, including students' and instructors' opinions on the subject. The study is important as the first study on feasibility of this learning model for cello education. Moreover, there are no studies in the literature on the feasibility of the model for any field of Turkish music education. The study is also important as the first study on feasibility of this model in Turkish Music. It is believed that the data from this study can guide academicians and educational institutions on how the communication and learning environments for cello education should be arranged under the flipped learning approach.

\subsection{Purpose of Study}

This study is aimed at receiving students' and instructors' opinions on the feasibility of flipped learning model for cello education in Turkish music. Additionally, the effects of flipped learning on students' success in right hand-left hand techniques on cello, rhythms, maqam transitions, nuance signs, musical interpretation, fluency, and performance of Turkish Music pitches on cello were examined.

\section{Method}

\subsection{Research Model}

This is a qualitative study designed to ensure cello students studying at Turkish Music Conservatory of Yildirim Beyazit University to keep practicing on their instruments during the mid-term break (twenty days) and spend the holiday time effectively. This is the first study to examine the use of this model in Turkish Music education and in cello classes. Opinions on the implementation of the model were obtained through semi-structured interviews separately prepared for students and instructors.

\subsection{Study Group}

The study group of the research was created by criterion sampling, which is a purposeful sampling method. The students were selected for the study group depending on the criteria that they must be chosen among students studying at Turkish Music Conservatory of Yildirim Beyazit University, they must have taken Turkish Music theory, Turkish Music forms and rhythms and basic cello courses for a period of minimum two years and received an average score above seventy points in those three courses. The study group consisted of three individuals, including one junior and two senior students, who fulfill the mentioned criteria. The criteria sought in selection of the instructors for the research required that the instructors must be chosen among academicians in cello branch, specialized in Turkish Music and have a minimum experience of five years. Three instructors fulfilling the mentioned criteria agreed to participate in the research and formed the study group. Therefore, the study group consists of three students studying at Turkish Music Conservatory of Yildirim Beyazit University in academic year 2017-2018 and three instructors from Cumhuriyet University, Ataturk University and Gaziantep University.

\subsection{Data Collection Process}

The musical piece selected for practice is Sultaniyegâh Pesrev, which contains various transitions in terms of maqam, quite large breadth of pitches, a large number of transitions between positions, various cello techniques and musical movements. Two experts in field of cello assisted in selection of the musical piece, and finally the mentioned piece was chosen as the most suitable one among five options which the researcher thought to have fulfilled the above listed criteria and suited the students' readiness levels.

The researcher made a tutorial video on how to perform Sultaniyegâh Pesrev, composed by Refik Fersan, on cello. 
Since Turkish Music pieces are composed and performed in treble clef regardless of instrument and this research is for Turkish Music education, Sultaniyegâh Pesrev was also written and performed in treble clef.

During the video shooting, suitable legatos and finger numbers were initially written for cello performance of Sultaniyegâh Pesrev, which was composed by Refik Fersan, and musical movements and nuance signs were added. The video contained details about bowing techniques used, their application on cello, positions and musical expressions used, maqam details, maqam transitions in the piece, and a full performance of the piece. The first part of the video was converted to a presentation via Microsoft Office 2010 PowerPoint and saved as a screenshot, and the video was edited on Camtasia Studio8 software. The video is available via the following link: https://www.youtube.com/watch?v=POk01aRWl3M.

The semi-structured interview form was used in the study. "Interview method is regarded as a useful method for obtaining full and accurate data on the subject of a qualitative research" (Judd, Smith and Kidder, 1991, 253). "In semi-structured interviews, interview questions and subjects are outlined, yet the researcher can steer the course of the interview and ask new questions depending on the answers" (Berg, 1998, 61). Two separate semi-structured interview forms were prepared for students and instructors in the study. The interviews held targeted acquiring in-depth data on the feasibility of the flipped learning method for cello education in Turkish Music.

The interview form prepared for the students by the researcher contained questions about the cello education received by the students until the date of the study, implementation process of the flipped learning method, structure of the video used in practice, feasibility of the method for cello education in Turkish music, its advantages and disadvantages, students' opinions on whether they would study by this method, and related suggestions. The interview form prepared for the instructors contained questions about assessment of students' video recordings of their instrumental performance before and after the implementation, aspects in which improvement or deterioration from the previous performance was detected, structure and efficiency of the video prepared, feasibility of the system for instrument education in Turkish Music, instructors' opinions on whether they would apply the method on their students, and related suggestions.

The implementation process of the research is the mid-term break of the academic year 2017-2018 and the subsequent twenty-day period. The students initially performed Sultaniyegâh Pesrev, which they studied by conventional methods, on cello. The students participated in the class twenty days after the video prepared by the researcher was sent to them, and each was asked to perform that particular piece. The performances before the video, during the class and after the implementation were recorded in video format. Three interviews were held with students, including during the implementation process, during students' practices by using the video as a tutorial (10th day) and after the practice class. All interviews held were subject to content analysis and issued in form of report.

To ensure diversity of data and strengthen the study in terms of validity-reliability, data were collected from the instructors via two different data collection tools. The mentioned data collection tools included student evaluation form and semi-structured interview form, which were prepared by the researcher under supervision of two experts specialized in educational sciences. The instructors were asked to view the students' all performances before and after the practice class, along with the practice tutorial video and the video of the practice class. The instructors were asked to fill out the evaluation forms for each student and for separate stages as before and after the implementation. Following the listening and evaluation process, individual interviews were held with the instructors. The interviews were conducted after the processes of learning by video and practicing accompanied by instructors at school. All interviews held were subject to content analysis and issued in form of report. The data from personal interviews held with the instructors and the data from the evaluation forms filled out by the instructors were checked in terms of consistency. Similarities and differences identified are addressed in the findings section.

\subsection{Collection of Data}

The data collection tools of this study include literature review, semi-structured interview form applied to students who were subject to the flipped learning model, semi-structured interview form applied to instructors to evaluate former and latter performances, student evaluation form prepared for rating by instructors, previous video recordings of each student -in which they performed by conventional methods-, subsequent video recordings of each student after practicing with the video and taking the practice class, video recording of the class after practicing with the video, and students' transcripts containing their grades in cello course from the first year of their undergraduate education.

\subsection{Analysis of Data}

The data from semi-structured interviews held with students and instructors and the data from student evaluation forms of the instructors were separately assessed. The data from the interviews were recorded by a voice recorder and exported to computer environment and transcribed. The data were analyzed by using the content analysis method. During the content analysis, themes were created according to the students' answers, and the data were encoded on the 
themes created. Two other qualitative expert researchers studying in field of education assisted in ensuring reliability of the themes and coding determined by the researcher. Similarly, the mentioned experts determined the themes and coding for the research. Details subject to difference of opinions were re-discussed and concluded. The results achieved were compared and the analysis process was completed with necessary corrections and revisions.

The data from the interviews with the instructors and the data in the student evaluation form were compared to identify and interpret consistent and inconsistent data.

\subsection{Validity-Reliability}

"The principle of reliability is based upon the assumption that a single reality exists on a particular subject and the same result is achieved upon repetitive researches conducted on that subject. However, it is hard to ensure reliability for researches in social sciences as human behavior is unsteady" (Merriam, 1998, 205). Nevertheless, there are still available reliability approaches which suit the qualitative research method.

In this study, the content analyses conducted by two researchers specialized in field of education were compared by using the same information, and discrepancies identified were minimized. Detailed information was provided on the processes of data collection and analysis during the research; the interview and student evaluation forms were given their final form according to opinions of two experts experienced in qualitative researches.

Methodological triangulation refers to the use of multiple research methods and techniques to answer the same research question (Denzin, 1994). When different research methods are used for this purpose, it is hard to obtain data which are automatically consistent with and integrated to each other. Whereas, possible different results increase conclusiveness of the research results to a certain extent. As the use of different research methods in the same study will yield comparative results, the research will also have increased reliability (Patton, 1990). Methodological triangulation was applied in this study by using the data from the student evaluation form prepared by the researcher and from the semi-structured interview form.

\section{Findings and Comments}

\subsection{Teaching Method Before the Implementation}

This theme was obtained by encoding the answers to the question "how was your teaching method in the classroom before the implementation?", directed only to students. All the students gave similar answers to the question of how a classroom experience was before the implementation. According to the reported statements, the conventional teaching method involved arrangement of pieces including finger numbers, bow signs, nuances, etc., depending on students' levels, to be given as assignments before the class, teaching in the classroom through active participation of students who practiced on the assignment, and ensuring students to acquire targeted skills through accompaniment and interpretation.

\subsection{Implementation Process}

This theme was obtained by encoding the answers to the question "how was the implementation process of flipped learning method", directed only to students. Regarding the implementation process, S2 stated:

The implementation process was very productive. We always listen to Turkish Music pieces. But it's important to see how they are performed on cello, and how bow and finger numbers are used. And it was like a real class with all the detail provided. If I was asked by my instructor to practice on a particular piece, I would practice but probably could not get the same results. The video really motivated me. I had the opportunity to pause the video when I needed, and accompany the performance on the video.

S2 reported that he felt like as if he was having a class with his instructor and he was motivated to practice, which is an important detail indicating that the student well spend the implementation process. S3 reported the following regarding the implementation process.

The instructions in the tutorial allowed me to practice along with the video. In fact, I started by taking a look at it and listening. Later on, I noted down the instructions on the written score and played the partitions (hâne) one by one. When I got to the final part where the instructor says "play along with me", I had the opportunity to play along with the instructor on the video without having to be in the classroom. I could play the video whenever and wherever I wanted. So it was very helpful for me.

S1 reported similar statements to his peers, with the exception that he addressed the importance of the practice class at the final stage of the implementation process, which they stated to be as essential as the process of practice along with the video. It is concluded from the statements that the students paid efforts to make the best use of the implementation process, practiced according to the tutorial video systematically, and identified their flaws and corrected their mistakes during the practice class forming the final stage of the implementation process. 


\subsection{Student Performances Before the Implementation}

Regarding the students' performance before the flipped learning model, I1 reported: "The video recordings before the implementation reveal that the students played only the notes, without considering any factors such as use of positions, bowing techniques, etc. They have a command of the cello techniques but they were then unaware of how to use those techniques in Turkish Music pieces. For example, but they crossed strings in the first position". Other instructors reported similar statements on that topic. During the interviews, it was revealed that students were not satisfied with their performances before the implementation. For instance, S1 voiced his discontent with his initial performance by reporting: "When I analyzed the piece without getting help, I only gained a basic understanding of the piece but failed to notice the nuances. Or I couldn't fully grasp the piece, I had to do a careful listening, my performance needed real improvement".

Both instructors and students addressed the deficiencies in former performances before the flipped learning model, and emphasized that those performances were not satisfactory.

\subsection{Student Performances After the Implementation}

Regarding that topic, I1 reported: "Following the implementation of flipped learning method, two students performed at such a satisfactory level that it was quite unlike their initial performance. It seems that they successfully applied the imitation method". With the statement above, I1 emphasized that the 'imitation' element in mesk method, the most important teaching method in instrument education in Turkish music, can be supported by this model. As a remarkable statement, I2 reported: "There were quite outstanding differences after the implementation. I observed that the student with the poorest initial performance displayed the most successful performance after the implementation". The student who displayed the poorest performance in the video recording stage designated as the preliminary test before the implementation, made the best progress after the implementation, which is significant as it highlights differences between students' learning styles. Whereas, I3 reported: "It seems that the students worked harder and achieved better concentration. They seem to have paid effort to perform the piece by imitating the style shown in the video and paying attention to musical expressions and details". With his statement above, I3 emphasized that the students displayed their performance by paying attention to details and musical expressions.

Regarding the topic, the instructors reported that differences between students' individual learning styles should be considered and the 'imitation' element in mesk method, the most important teaching method in instrument education in Turkish music, can be supported by flipped learning model. Additionally, it was emphasized that the students displayed their performances by considering details and musical expressions.

\subsection{Participant Behaviors Subject to Change After the Implementation}

This theme was obtained by encoding the answers to the question 'what are the aspects of student behaviors in which improvement or deterioration from the previous performance was detected before and after the implementation?', directed only to instructors. I1 answered that the students made the best progress in the use of positions. I2 and I3 reported that the students made the best achievements in integrity, fluency, musical interpretation, and right hand-left hand techniques. Unlike the other instructors, I2 indicated that the students made progress in the use of rhythms. All the instructors emphasized that the students displayed much better performances after the implementation of the flipped learning model than before such implementation. However, all the instructors agree that no great progress has been achieved in producing clean pitches of Turkish Music.

\subsection{Structure and Efficiency of the Practice Tutorial Video}

This is one of the themes most commonly coded in line with the answers to the question 'How was the structure and efficiency of the practice tutorial video used?', directed both to students and instructors. The practice tutorial video was found successful by all the participants. I2 reported his opinions on the video by stating: "The practice tutorial video made an efficiently introduction of the price and contained good instructions. Students are rather expected to have a grasp of technical skills under an instructor's supervision. In this sense, it is helpful to create a practice based on the piece". Despite the foregoing, I2 added "But I really wonder what kind of results would be obtained if this method was used for teaching a technical skill (bowing technique, left hand technique, or trill or glissando in Turkish Music, etc.)", suggesting that a particular technique must be introduced in a video and then applied through a practice tutorial, rather than teaching a technique within a musical piece. I3 reported his opinions on the video: "The practice video used was quite impressive. The video includes all details about positions, nuances, maqam transitions. I couldn't find anything that needs to be added. It is an outstanding video contributing to students". I3 also added his suggestions on future practices, stating: "Musical pieces with more maqam characteristics can also be selected for practice. Perhaps it will yield quite different results. This video already contains transitions in Usak, Hicaz and Saba. Yet another option may involve practices on pieces containing more pitches of Usak, Dik Hisar, Hisar, Evc, Segâh." 
In addition to the instructors, the students also addressed this topic; they reported their opinions when answering not only to this question but also the other questions. S1 reported:

The instructions in the practice tutorial video were very clear and effective. During the mid-term break, I felt that the video alone was quite effective, and I didn't need schooling. The video made it quite easy to keep track of the notes while listening to the instructor and seeing his playing style. The full performance of the musical piece at the final part of the video was helpful as it allowed us to evaluate our own performance by listening to the entire piece and playing along. I listened to the video repeatedly, and noticed different details every single time. It was definitely quite useful.

Other students made similar statements to those of S1, often expressing their content with the availability of both the notation and the video, and the 'play along' part at the final part of the video. Unlike the other students, S2 reported: "This video was quite easy to practice along, so I wasn't intimidated. This was an advantage of the video. The instructions were slow enough for me to catch, which is good, and I could pause the video whenever I needed. This was a quite interactive experience, just like in the classroom". The foregoing statements are important as they provide data evidencing that the video suited the students' levels.

Students often reported their content with the ease of access to the tutorial video anywhere at any time, and the opportunity of playing along with an instructor at any time and as often as they want. Whereas, regarding the structure of the video, both students and instructors reported positive opinions on the 'accompaniment' part at the end of the video. This part can be regarded as a discipline whereby the mesk method, the most important teaching method in instrument education in Turkish Music, is combined with technology.

\subsection{Advantages and Disadvantages of the Conventional Teaching Method}

This theme was obtained by encoding the answers to the question 'what are advantages and disadvantages of the conventional method', directed only to students as they had the opportunity to learn the conventional method and the flipped learning model by experience. On this theme, S1 reported: “The conventional teaching method doesn't go beyond the method, it focuses on details such as the syllabus, form of teaching, curriculum, etc. But when it goes beyond the method, better interaction can be guaranteed between the students and the instructor. The educational model to be chosen should be student-oriented". With the foregoing statements, S1 underlined an important topic, indicating that instrument education which is provided individually, must be based on a method which is suitable for the student. On the same theme, S3 reported that the mesk method is indispensable in Turkish Music teaching, yet the time designated for interaction between the instructor and the students is limited unlike in the past, and therefore the mesk method cannot be fully maintained as it used to be. At this point, teaching models involving the use of technology, such as the flipped learning system, can be employed. Conveying some of the essential information to the students by means of videos before the class can be a solution, even if partially, to this problem by assuring more efficient use of the time spent with the instructor.

\subsection{Advantages and Disadvantages of the Flipped Learning Model}

This theme was obtained by encoding the answers to the question 'what are advantages and disadvantages of the flipped learning model', directed only to students as they had the opportunity to learn the conventional method and the flipped learning model by experience. Regarding the theme, S1 reported: "This model enables us, unlike in the conventional method, to learn a subject in further detail and to have a grasp of the maqam, see and analyze any other technical details on the piece. I think this model doesn't have any disadvantage". On the same theme, S3 reported: "The flipped learning model is quite exhaustive and it offers faster access to achievement when compared to the conventional method." Statements of S1 and S3 include a comparison between the conventional method and the flipped learning model, indicating that the flipped learning model provides faster access to achievement, and it is more exhaustive and detailed. On the same theme, S2 reported that cello is a fretless instrument, which may cause the student to forget how to produce clean pitches of Turkish Music on cello, or how they sound, and that this problem could not be overcome due to a number of reasons including the lack of visual and auditory sources in cello education in Turkish Music. Emphasizing that the methods to be used in individual instrument education should be custom-tailored to students' needs, S2 mentioned that he found the flipped learning model to be quite effective. Furthermore, S2 reported that students would not experience problems in understanding the instructions in the video as they are already familiar with their instructor, and they would grasp the instructor's instructions in the same way in his/her absence. S2 reported that the instructor's preparation for the class and video shooting motivated him to practice, so the flipped learning method allowed a more efficient learning experience. In fact, S2's statements summarized the advantages of the flipped learning model.

Students think that the use of the flipped learning model is helpful as it enables them to do a more detailed practice with the instructor and prepare them systematically. 


\subsection{Feasibility of the Flipped Learning Model for Use in Cello Education in Turkish Music}

This is one of the themes most commonly encoded, in line with the answers to the question 'Can you tell about your opinions on the feasibility of this method in cello education in Turkish Music?', directed both to students and instructors. Regarding this theme, I1 reported: "Instructors just inform the students about what piece they should practice for the class, and students do the practice by merely using their own knowledge. The essential detail in this method is the availability of visuals showing correct application of techniques so that students will learn how to practice accordingly. I think it is useful in that sense". I1's statements emphasized the advantage of the flipped learning model as it ensures students to prepare themselves correctly. I2 addressed the lack of methods and etudes in cello education in Turkish Music, emphasizing that the use of such methods in cello education in Turkish Music is important in this context. Stating that Turkish Music requires a training which is to be rather based on visual and auditory sources, I2 underlined that the implementation of this model is crucial in Turkish Music since it will enable students to listen to and view techniques repeatedly and contribute to the teaching materials needed in this field. On the same theme, I3 stated that the model is a fully conscious and effective approach in technical, educational and scientific terms, also reporting: "After the implementation of the flipped learning system, I observed an increase in all the listed categories of achievement among students in general. I think that the implementation of this system will definitely increase success. Such increase that was observed after a single application will provide far better achievements as the method will be used regularly". With his expression "in all the listed categories of achievement" in the foregoing statement, I3 refers to correct application of the rhythm mentioned in the evaluation scale, correct use of right hand-left hand techniques, correct performance of maqam transitions, correct application of nuance signs, musical interpretation, fluency, and the skill to perform Turkish Music on cello.

On the same theme, S1 reported: "I know that this implementation is quite challenging and time consuming. But I still think that this method will be highly useful when implemented". With the expressions 'challenging' and 'time consuming', S1 refers to the activities which must be assumed by the instructor, such as shooting videos, editing, etc. In this context, S1 underlined that such activities may be time consuming for instructors, yet they are still quite useful for students. Whereas, S2 reported that this practice has a positive effect especially on the elimination of students' intonation problems. S2 mentioned that a flipped learning model to be formed by videos to be arranged depending on students' levels would bring them to success. On the same theme, S3 reported: "It's an amazing system, I'm really happy to be introduced to it. I hope I will get the chance to make progress and teach the same to others in the future". The interviewed students, who experienced the flipped learning model and who are about to complete their education, stated that they are pleased to have been introduced to this system and they will use this method if they become instructors, which clearly shows that they consider the flipped learning model to be feasible for use in Turkish Music instrument education.

\subsection{The Current Status of Use of Teaching Methods and Techniques in Turkish Music}

This theme was created according to data from the information provided by the instructors. The predominant opinion among the interviewed instructors is that teaching methods and techniques are not adequately used in Turkish music. On this theme, I2 stated that there are very few sources on teaching methods in Turkish Music, also reporting: "As far as I observe, there has been no procedure aimed at such type of teaching models". As a striking observation, I2 reported that there has been no reference to any method or teaching model other than the mesk method, which is used as a conventional method in instrument education in Turkish Music. This observation brings to mind the question of why no other teaching method has been used. The following statements of I 3 can be regarded as an answer to that question: "Such methods can be used in Turkish music education, but as far as I see, they are not in use. Instructors do not prefer them, as they may be difficult. But if they are implemented, they will guarantee an education which will provide technical and scientific contributions". I3's foregoing statements addressed the possibility that instructors may be refusing to use these methods in Turkish Music as they seem difficult.

\subsection{Potential Drawbacks of the Implementation of Flipped Learning Model}

Some of the instructors reported opinions on potential drawbacks of the implementation of the flipped learning model although there was no question designated under the said theme. This theme was created according to the opinions stated in that direction. On the said theme, I1 anticipated that the students will memorize the pieces in the videos to be prepared by the instructors and play them by rote. I1 reported: "I think that the guide must be notation, I disapprove imitation. Therefore, I believe that the use of this method alone will remain inadequate in instrument education. This method should be used as a supportive education". I1's foregoing statements emphasize that the flipped learning model alone cannot be a method of instrument education in Turkish Music but can be used to support the conventional method. Moreover, I3 reported his/her concerns about the implementation: "Will it be possible for students to use this model to be able to perform a Turkish music piece fluently with its characteristic strains and give the feeling of the piece? I have 
concerns about it. And what's more, one-to-one teaching is more effective as it would be possible to correct any mistakes as they occur".

The instructors think that it would be helpful to use this model in instrument education in Turkish Music, but the use of the model alone or as the fundamental teaching method would not be suitable. The instructors think that using this model to support conventional teaching method will bring success.

\subsection{Suggestions}

This section includes suggestions by the instructors and the students on the implementation of the flipped learning system in cello education in Turkish Music.

Suggestions on the timing of implementation of the flipped learning model were made solely by the instructors. Regarding the theme, I1 suggested as follows: "The flipped learning model should be applied to senior students, not to beginner level students." Similarly, I3 addressed the importance of the correct use of cello performance techniques, nuances, fluency, maqam characteristics and style, indicating that these must be all regarded as a whole, and students lacking required amount of relevant knowledge and skills will have difficulty. As in the foregoing, the instructors regard the model as an advanced training like masterclass, and argue that applying this model to students possessing a certain extent of instrumental control and playing technique will increase success.

S3 made suggestions on making the method permanent, reporting as follows: "I would strongly favour a workbook containing various maqams and pieces, indicating details such as bow signs, finger numbers, etc. and an accompanying $\mathrm{CD}$, including video instructions for all the pieces in the workbook, as in the practice tutorial video". S3's foregoing statement indicates that new practice tutorial videos should be made available and be arranged as a useful and permanent part of the method.

\section{Results and Discussion}

According to the data from the interviews held with the students, the conventional teaching method involves arrangement of pieces including finger numbers, bow signs, nuances, etc., depending on levels of students, to be given as assignments before the class, teaching in the classroom through active participation of students who practiced on the assignment, and ensuring students to acquire targeted skills through accompaniment and interpretation. It is concluded from the statements made regarding the implementation process of the flipped learning model that the students paid efforts to make the best use of the implementation process, practiced according to the tutorial video systematically, and identify their flaws and correct their mistakes during the practice class which forms the final stage of the implementation process.

Both instructors and students addressed the deficiencies in former performances before the flipped learning model, and emphasized that those performances were not satisfactory. All the instructors highlighted the fact that the students displayed much better performances after the implementation of the flipped learning model than before such implementation.

The interviews held with the instructors and the evaluation scale data obtained revealed that, following the implementation, students made achievements in all the following categories: rhythms, right hand-left hand techniques, maqam transitions, nuance signs, musical interpretation, fluency, and performing Turkish Music pitches on cello. However, all the instructors agree that no great progress has been achieved in producing clean pitches of Turkish Music. The biggest progress was reported to be in categories of fluency and musical interpretation. While the data from the interviews and from the evaluation forms were consistent, there were some minor differences as well. During the interviews, it was reported that the categories in which biggest progress was achieved were fluency and musical interpretation, as also evidenced by data from evaluation forms. On the other hand, the data from the evaluation forms reveal that using the left hand techniques correctly and performing Turkish Music on cello are the categories in which biggest progress was achieved. Whereas, the students reported that this practice has a positive effect especially on the elimination of their intonation problems.

According to the data from the interviews held with the instructors, it has been revealed that differences between students' individual learning styles should be taken into account and the 'imitation' element in mesk method, the most important teaching method in instrument education in Turkish music, can be supported by flipped learning model. Additionally, it was emphasized that the students displayed their performances by considering details and musical expressions.

Although the practice tutorial video was found successful, instructors suggested that musical pieces should be selected among those with more maqam transitions, and this type of practices should be increased only through a technical teaching video to be prepared. 
Students often reported their content with the ease of access to the flipped practice tutorial video anywhere at any time, and the opportunity of practicing in company with an instructor at any time and as often as they want, which is considered as the most advantageous aspect of this method. Whereas, regarding structure of the video, both students and instructors reported positive opinions on the 'accompaniment' part at the end of the video. This part can be regarded as a discipline whereby the mesk method, the most important teaching method in instrument education in Turkish Music, is combined with technology. During the interviews, students reported that not only the conventional method but also various other teaching methods and techniques should be used. It was reported that the mesk method used in the conventional teaching method in cello education in Turkish Music is the most important method in Turkish Music teaching. Nevertheless, it was reported that the time designated for interaction between the instructor and the students is limited unlike in the past, and therefore the mesk method cannot be fully maintained as it used to be, and teaching models involving the use of technology, such as the flipped learning system, can be employed at this point. Conveying some of the essential information to the students via practice videos can be a solution, even if partially, to this problem by assuring more efficient use of the time spent with the instructor. In this sense, the flipped learning system is introduced as a method to turn the disadvantage into advantage in today's educational environment with less time dedicated to the student, contrary to the past when instrument education in Turkish Music involved one-to-one teaching and longer interaction between the instructor and the student and longer time for practice in class.

All the participants had positive opinions on the use of the flipped learning model in cello education in Turkish Music. Students think that it would be helpful to use this system to ensure a more in-depth practice, go into detail and prepare themselves more systematically. The students think that the flipped learning model provides faster access to achievement than the conventional method, and is more exhaustive and detailed. It was emphasized that cello is a fretless instrument, which may cause the student to forget how to produce clean pitches of Turkish Music on cello during classroom activities or how the pitches sound, and that this problem could not be overcome due to a number of reasons including the lack of visual and auditory sources in cello education in Turkish Music. Also, it was reported that the instructor's preparation for the class and video shooting motivate the student to practice. It was stated that the methods to be used in individual instrument education should be custom-tailored to students' needs, students would not experience problems in understanding the instructions in the video as they are already familiar with their instructor, and they would comprehend the instructor's instructions in the same way in his/her absence. The predominant opinion is that the implementation of such model while the conventional method is in use will provide a more efficient and productive for interaction between the students and the instructor. The interviewed students, who experienced the flipped learning model and who are about to complete their education, stated that they are pleased to have been introduced to this system and they will use this method if they become instructors, which clearly shows that they consider the flipped learning model to be feasible for use in Turkish Music instrument education.

All the instructors reported that the flipped learning model can be used in cello education in Turkish Music and they even emphasized the benefit of its use. They addressed the lack of methods and etudes in cello education in Turkish Music, emphasizing that the use of such methods in cello education in Turkish Music is crucial in this context. The instructors also underlined the advantage of the flipped learning model as it ensures students to prepare themselves correctly. Whereas, students think that a flipped learning model to be formed by videos to be arranged depending on their levels would increase success.

During the interviews, all the instructors reported that they want to apply this model to their students, and all the students reported that they would favour practicing by using this model. The instructors reported that no other method or teaching model was referred to other than the mesk method, which is used as the conventional method in instrument education in Turkish Music, and different methods should be used in teaching in support of the conventional method. The instructors have certain concerns that, for example, students may tend to memorize pieces rather than read notes, thus it would not be possible for students to be able to perform a Turkish music piece with the style as required and to accurately give the feeling of the piece by using this method, or students may develop incorrect techniques, style, etc.. Due to the mentioned concerns, the instructors report that the flipped learning model alone cannot be a method of instrument education in Turkish Music but can be helpful when used to support the conventional method. Furthermore, the instructors think that the flipped learning model should be applied to students who possess the maqam knowledge, right hand-left hand techniques on cello, etc., so that bigger success will be achieved. The instructors, regarding the model as an advanced training like masterclass, argue that applying this system to students possessing a certain extent of instrumental control and playing technique will increase success.

During the interviews, it was found out that the students were quite interested in implementing the flipped learning method, and they even thought that it should be a fundamental teaching method, and they would favour to take the class always by using this method. The instructors reported that this model increased the students' success, and stated that they are interested in using this model. However, unlike the students, the instructors think that this model alone cannot 
be a method of instrument education in Turkish Music but can be used to support the conventional method. While students reported hardly any negative opinion on the flipped learning system involving the use of technology, the instructors had concerns about the implementation of this system alone. Although there is no exact opposition between the opinions, one group is willing to use the flipped learning model without hesitation while the other considers the model only as a supportive method, which is thought provoking. Considering that the instructors interviewed were born between 1960-1980 and the students interviewed were born between 1990-2000, the change between generations in respect of opinions on the flipped learning system involving the use of technology will be understood more clearly. This may either be considered as a difference of opinions between generations or as a state of deliberation acquired by the instructors with knowledge and experience.

Acting from the data from the research, it is suggested that the flipped learning model should be used to support the conventional method in cello education in Turkish Music. This model can be used for practicing in long holidays such as mid-term breaks, summer vacations, or in the ordinary course of cello lessons. In the view of the interviewed participants' opinions, it can be concluded that the flipped learning model can be applied to junior or senior undergraduate students studying in Turkish Music conservatories and used for teaching of a particular technique or pieces with technical and musical challenges.

The data from the interviews held and the observations of the interviewees reveal that the flipped learning model is not used in cello education in Turkish Music. The use of the flipped learning model in cello education in Turkish Music primarily requires introduction of the model to experts of the field. For this purpose, workshops can be organized for the implementation of the flipped learning model in Turkish Music, and stakeholder opinions can be received.

There has been no study in Turkish Music which focuses on the flipped learning model, which is a rarely known subject in field of music. This study on cello education can also be applied to other fields of Turkish Music to examine the feasibility of the model.

\section{References}

Abeysekera, L., \& Dawson, P. (2015). Motivation and cognitive load in the flipped classroom: definition, rationale and a call for research. Higher Education Research \& Development, 34(1), 1-14. https://doi.org/10.1080/07294360.2014.934336

Ash, K. (2012). Educators view 'flipped' model with a more critical eye. Education Week, 32(2), 6- 7.

Berg, L. B. (1998). Qualitative research methods for social sciences. Boston: Allyn \& Bacon.

Bergmann, J., \& Sams, A. (2012). In Flip your classroom; Reach every student, in every class, every day (1st.ed.). Washington, DC: International Society for Technology Education.

Bishop, J. L., \& Verleger, M. A. (2013). The flipped classroom: A survey of the research. In ASEE National Conference Proceedings (Vol. 30, No. 9, pp. 1-18). Atlanta, GA.

Bosner, S., Pickert, J., \& Stibane, T. (2015). Teaching differential diagnosis in primary care using an inverted classroom approach: student satisfaction and gain in skills and knowledge. BMC Medical Education, 15(1), 63. https://doi.org/10.1186/s12909-015-0346-x

Denzin, K. N. (1994). "Triangulation in educational research". In Husen, T. \& Postlethwaite, N. (Ed.). The international encyclopaedia of education (pp. 6461-6466). London, England: Pergamon.

Fulton, K. (2012). The flipped classroom: transforming education at Byron High School: a Minnesota high school with severe budget constraints enlisted youtube in its successful effort to boost math competency scores. THE Journal (Technological Horizons In Education), 39(3), 18.

Gannod, G. C., Burge, J. E., \& Helmick, M. T. (2008, May). Using the inverted classroom to teach software engineering. International Conference on Software Engineering (pp.777-786). Leipzig, Germany: ACM. https://doi.org/10.1145/1368088.1368198

Johnson, L., Becker, S., Estrada, V., \& Freeman, A. (2014). NMC horizon report: 2014 higher education edition. Austin, Texas: The New Media Consortium.

Judd, C. M., Smith, E. R., \& Kidder, L. H. (1991). Research methods in social relations, United States: Cengage Learning, Inc.

Kertil, M. (2008). Investigation of problem solving skills of prospective mathematics teachers in modeling process. (Master's thesis, Marmara University, Istanbul, Turkiye). Retrieved March 02, 2018, from https://tez.yok.gov.tr/UlusalTezMerkezi/

Kocabatmaz, H. (2016). The ideas of teachers regarding the "flipped classroom model. Journal of Research in 
$\begin{array}{lllll}\text { Education } \quad \text { and } & \text { Teaching }\end{array}$ http://www.jret.org/FileUpload/ks281142/File/02a.handan_kocabatmaz.pdf

Merriam, S. B. (1998). Qualitative research and case study applications in education. Revised and expanded from "case study research in education”. San Francisco, CA: Jossey- Bass Publishers.

Moraros, J., Islam, A., Yu, S., Banow, R., \& Schindelka, B. (2015). Flipping for success: evaluating the effectiveness of a novel teaching approach in a graduate level setting. BMC Medical Education, 15(1), 27. https://doi.org/10.1186/s12909-015-0317-2

Moravec, M., William, S. A., Aguilar R. N., \& O’Dowd D. K. (2010). Learn before lecture: a strategy that improves learning outcomes in a large introductory biology class. CBE Life Sciences Education, 9(4), 473-481. https://doi.org/10.1187/cbe.10-04-0063

Mortensen, C. J., \& Nicholson, A. M. (2015). The flipped classroom stimulates greater learning and is a modern 21st century approach to teaching today's undergraduates. Journal of Animal Science, 93(7), 3722-3731. https://doi.org/10.2527/jas.2015-9087

Patton, M. Q. (1990) Qualitative evaluation and research methods (2nd ed.), Thousand Oaks, CA, US: Sage Publications.

Phillips, C. R., \& Trainor, J. E. (2014). Millennial students and the flipped classroom. Journal of Business and Educational Leadership, 5(1), 102-111.

Sirakaya, D. A. (2017). Student Views on Gamified Flipped Classroom Model. Ondokuz Mayis University Journal of Education Faculty, 36(1), 114-132. Doi:10.7822/omuefd.327393

Strayer, J. F. (2011). The teacher's guide to flipped classroom. Retrieved from: http://www.edudemic.com/guides/flipped-classrooms-guide/

Talbert, R. (2012). Inverted classroom. Colleagues, Article 7, 9(1), 18-19. https://scholarworks.gvsu.edu/colleagues/vol9/iss1/7

Tan, E., Brainard, A., \& Larkin, G. L. (2015). Acceptability of the flipped classroom approach for in-house teaching in emergency medicine. Emergency Medicine Australasia, 27(5), 453-459. https://doi.org/10.1111/1742-6723.12454

Toto, R., \& Nguyen, H. (2009, October). Flipping the work design in an industrial engineering course. 39th IEEE International Conference on Frontiers in Education Conference, San Antonio, TX, USA. https://doi.org/10.1109/FIE.2009.5350529

Tune, J. D, Sturek, M., \& Basile, D. P. (2013). Flipped classroom model improves graduate student performance in cardiovascular, respiratory, and renal physiology. Advances in Physiology Education, 37(4), 316-320. https://doi.org/10.1152/advan.00091.2013

Verleger, M. A., \& Bishop, J. L. (2013, June). The flipped classrom: A survey of the research. 120th ASEE National Proceedings, 30(9), (pp. 1-18). Atlanta, GA. Retrieved from file:///C:/Users/Toshiba/Downloads/6219\%20(5).pdf

Wetterlund, K. (2008). Flipping the field trip: Bringing the art museum to the classroom. Theory Into Practice, 47(2), 110-117. Retrieved from https://doi.org/10.1080/00405840801992298

Wong, T. H., Ip, E., J., Lopes, I., \& Rajagopalan, V. (2014). Pharmacy students' performance and perceptions in a flipped teaching pilot on cardiac arrhythmias. American Journal of Pharmaceutical Education, 78(10), 185. https://doi.org/10.5688/ajpe7810185

Zownorega, S. J. (2013). Effectiveness of flipping the classroom in a honors level, mechanics-based physics class. (Unpublished master's thesis, Eastern Illinois University, Charleston, Illinois). Retrieved from http://thekeep.eiu.edu/theses/1155

\section{Copyrights}

Copyright for this article is retained by the author(s), with first publication rights granted to the journal.

This is an open-access article distributed under the terms and conditions of the Creative Commons Attribution license which permits unrestricted use, distribution, and reproduction in any medium, provided the original work is properly cited. 